\title{
Think Tank: Relatório Estratégico sobre Publicação Científica Biomédica em Portugal
}

\author{
Think Tank: Strategic Report on the Scientific Biomedical Publication \\ in Portugal
}

Rui Tato MARINHO ${ }^{1,2}$, Helena DONATO ${ }^{3,4}$, Fernando FERNANDEZ-LLIMOS ${ }^{3,5}$, João MASSANO Miguel ALMEIDA ${ }^{3,10}$, José CARONA CARVALHO ${ }^{11}$, Tiago VILLANUEVA ${ }^{3,12}$, João Eurico FONSECA ${ }^{13,14}$

Acta Med Port 2014 Jan-Feb;27(1):1-3

\section{INTRODUÇÃO}

"Without publication, science is dead". Scientific American, Gerard Piel.

A actividade científica é tradicionalmente medida pelo número de artigos publicados em revistas com arbitragem científica (peer review).

Publish or Perish - todos nós já ouvimos ou lemos estas palavras. O número e qualidade de artigos publicados são factores relevantes que podem decidir uma carreira. A autoria de publicações peer reviewed é uma métrica de sucesso.

Aprender a estruturar, submeter e rever um artigo, são competências que desde cedo devem ser desenvolvidas nas Escolas Médicas. Produzir um mau manuscrito só atrasará ou evitará a publicação de bom material científico.

Investigação que não é nova, inovadora ou interessante, também não será publicada numa revista de reputação.

Com este documento pretendemos dinamizar a publicação de bons artigos científicos realçando que há muitas maneiras de se certificar que um manuscrito não é rejeitado antes de ser submetido ao peer review.

\section{Pontos-chave (Top Ten Think Tank)}

1. "Medical writing is a very important national and international key issue."

2. Semi-profissionalização dos Editores-Chefes (necessidade de contrato, compensação monetária ou em bolsa de horas).

3. Necessidade de competências em Escrita Científica - Formação obrigatória nas Faculdades de Medicina, alocar nos internatos tempo para a escrita científica, etc.

4. Equipa Editorial multidiferenciada.
5. Edição e fluxo electrónico do artigo.

6. Melhoria da qualidade científica dos artigos e das revistas.

7. Ética: considerar o Peer Review como um dever de cidadania científica, entender o conceito da moderna autoria científica.

8. Aceitar a rejeição.

9. Considerar a moderna bibliometria (factor de impacto, divulgação electrónica, web, downloads, etc).

10. Ampliar a internacionalização das publicações científicas portuguesas (Task Force).

\section{A publicação científica biomédica}

- A publicação científica médica tem relevância pessoal (curricular, formação global, comunicação, bolsas), institucional (Serviço, Faculdade, Hospital), nacional e internacional. A autoria confere crédito - tem importantes implicações académicas, sociais e financeiras.

- A publicação científica biomédica reveste-se de grande importância para a sociedade em geral, contribuindo para a melhoria da qualidade da prática médica e dos avanços científicos.

- Em medicina, a publicação científica é uma extensão da actividade clínica.

- A formação em escrita científica deve estar presente nos planos curriculares de ensino médico pré e pós-graduado, com carga horária que garanta formação de qualidade e que permita aos estudantes e jovens médicos entrarem directamente para o mundo da publicação científica médica.

- O tema da publicação científica deve ser presença

1. Editor-Chefe. Acta Médica Portuguesa. Lisboa. Portugal.

2. Serviço de Gastrenterologia e Hepatologia. Hospital de Santa Maria. Faculdade de Medicina de Lisboa. Portugal.

3. Editor-Associado. Acta Médica Portuguesa. Lisboa. Portugal.

4. Serviço de Documentação. Centro Hospitalar e Universitário de Coimbra. Coimbra. Portugal.

5. Instituto de Investigação do Medicamento (iMed.ULisboa). Departamento de Sócio-Farmácia. Faculdade de Farmácia. Universidade de Lisboa. Lisboa. Portugal.

6. Departamento de Neurociências Clínicas e Saúde Mental. Faculdade de Medicina. Universidade do Porto. Portugal.

7. Serviço de Neurologia. Hospital Pedro Hispano. Unidade Local de Saúde de Matosinhos. Matosinhos. Portugal.

8. Co-Editor. Acta Médica Portuguesa. Lisboa. Portugal.

9. Serviço de Medicina Interna. Centro Hospitalar e Universitário de Coimbra. Coimbra. Portugal.

10. Aluno Faculdade de Medicina da Universidade de Lisboa. Lisboa. Portugal.

11. Consultor de Sistemas de Informação. Acta Médica Portuguesa. Lisboa. Portugal.

12. Editorial Registrar. British Medical Journal. Londres. Reino Unido.

13. Unidade de Investigação de Reumatologia. Instituto de Medicina Molecular. Faculdade de Medicina de Lisboa. Lisboa. Portugal.

14. Serviço de Reumatologia. Hospital de Santa Maria. Centro Hospitalar Lisboa Norte. Lisboa. Portugal.

Recebido: 21 de Janeiro de 2014 - Aceite: 21 de Janeiro de 2014 | Copyright @ Ordem dos Médicos 2014 
obrigatória nos currículos de todas as Escolas Médicas do país com a carga horária de pelo menos 12 horas.

- As sociedades científicas médicas deverão ser facilitadoras da edição para os seus sócios (formação em escrita científica, exigência curricular, network nacional e internacional).

- No horário de trabalho deverão constar horas destinadas à produção científica, para: 'Parar para pensar', planear, desenhar estudos e escrever artigos científicos.

- Quando se elabora um estudo/projecto científico deve ser sempre que possível ponderado a escrita de um artigo científico.

- Para um correcto planeamento de um projecto científico que se quer publicado, deverá ab initio ser solicitado apoio especializado (em epidemiologia, estatística, evidência clínica).

- É mandatório ensinar: a pesquisar, estatística, epidemiologia, ética, elaboração de referências, elaboração de quadros e gráficos, rever artigos, etc.

- Deve ser constituída uma task force para impulsionar a edição e publicação médica original, em Portugal e no estrangeiro.

- O peer review é um tema chave e dos mais cruciais no âmbito da edição científica.

- A rejeição de artigos tem que ser entendida pelos autores como um processo habitual, corrente e culturalmente aceite ('cidadania científica').

- As revistas científicas portuguesas devem estar presentes em redes internacionais de edição e publicação científica.

- As revistas devem procurar indexação/inclusão em plataformas/bases de dados internacionais [SCIELO, Medline, Thomson-Reuters, PubMedCentral, Repositório Científico de Acesso Aberto de Portugal (RCAAP)].

\section{O Editor-Chefe}

- O cargo de Editor-Chefe é crucial numa revista científica e deve ser considerado como de elevada importância e especificidade. Nas revistas de alguma dimensão este deve ser objecto de compensação monetária e/ ou atribuição de bolsas horárias da própria instituição.

- Deve ser promovido um mínimo de estabilidade da função, idealmente por um período de três anos, para avaliação da repercussão do impacto do trabalho efetuado. Um ciclo de tempo inferior a três anos não permite, por exemplo, medir a evolução do Factor de Impacto ao longo do período de trabalho, tendo em conta que esta medição é obtida com base nas citações nos dois anos anteriores.

- O editor-chefe tem completa autoridade e independência para determinar o conteúdo editorial; Garante a qualidade da revista e de que o que publica é ético, actual e relevante para os leitores; Garante que todos os elementos envolvidos no processo de peer review devem actuar de acordo com os mais elevados padrões éticos; Decide sobre rejeições e aceitações.
- O editor-chefe é responsável pela linha editorial e pela gestão de reclamações.

- $\quad$ O editor-chefe de uma revista médica tem que ser médico.

\section{O artigo e o seu Fluxo}

- O fluxo do artigo é um processo muito complexo e de elevada exigência ética, prazos a cumprir, lisura de processos, etc.

- O fluxo dos artigos deve ser efectuado através de plataformas informáticas, como por exemplo o Open Journal System, ou outros sistemas semelhantes.

- $\quad$ O tempo que vai da submissão do artigo à publicação deve ser o mais curto possível. As revistas devem diminuir o tempo que vai desde a submissão a uma primeira decisão, bem como o período entre a aceitação e a publicação. A revisão do artigo pelos pares não deve exceder 2 a 4 semanas.

- As revistas científicas devem procurar a melhoria constante e a ampliação da sua mensagem científica, por vários meios, por exemplo através de agências de comunicação.

- A equipa administrativa, nas revistas de alguma dimensão, deve ter experiência ou formação nesta área.

- Plágio e publicação duplicada devem ser combatidos de forma sistemática, se necessário recorrendo a sistemas electrónicos de detecção.

- As revistas devem reger-se de acordo com as boas normas de edição biomédica:

o Uniform Requirement for Manuscripts Submitted to Biomedical Journals - International Committee of Medical Journal Editors (ICMJE);

o Committee on Publication Ethics (COPE);

o EQUATOR Network.

- Definir quem deve ou não ser um autor não é claro - editores e investigadores algumas vezes discordam, mas os Uniform Requirements do ICMJE dão orientação, indicam que cada autor deve ter participado significativamente no trabalho para tomar responsabilidade pública sobre o conteúdo e o crédito da autoria.

- O senior author de um artigo deverá ser entendido não como o mais sénior na carreira académica ou científica, mas como o que coordenou e tornou possível todo o processo que levou à publicação.

- $\quad$ Cumprir os quatro critérios de autoria (ICMJE):

o Têm uma contribuição intelectual substancial e directa no desenho e elaboração do artigo; ou participam na análise e interpretação dos dados;

o Participam na escrita do rascunho do manuscrito, ou na revisão crítica do conteúdo;

- Aprovam a versão final a ser publicada;

o Concordam que são responsáveis pela exactidão e integridade de todo o trabalho.

- O ICMJE preconiza ainda:

- Que os autores atestem na carta de apresentação (cover letter) que aprovaram a versão final do manuscrito; 
o Todos os envolvidos no estudo ou no manuscrito devem ser claramente mencionados, ou como autores na linha da autoria ou como colaboradores na secção agradecimentos;

o Os autores devem preencher os critérios específicos da autoria, e a ordem dos autores devem seguir princípios éticos;

o Todos os colaboradores que não encaixam nos critérios da autoria devem ser listados, após terem dado autorização por escrito, na secção Agradecimentos.

- Muitos autores desconhecem estes critérios, que devem por isso ser mais amplamente reconhecidos e usados. Para tal, devem ser sistematicamente ensinados ao longo da formação em medicina.

- A ordem dos autores na linha de autoria é uma decisão colectiva dos autores ou do grupo de estudo. Os Uniform Requirements sugerem que nada deve ser inferido a partir da ordem dos autores, porque convenções entre países, especialidades e grupos diferem.

- A questão da publicação em português e/ou em inglês: Para maior divulgação no mercado internacional e aumento do factor de impacto deve existir uma aposta franca no inglês, em versões bilingues, ou ainda a aceitação também em inglês, que induz progressivamente mais artigos nesta língua.

- $\quad$ O Brasil e os Países Africanos de Língua Oficial Portuguesa (PALOPs) podem e devem ser vistos como parceiros na divulgação e difusão de publicações científicas (a língua portuguesa é a $7^{a}$ língua mundial, falada por cerca de 250 milhões de pessoas).

- Deve ser privilegiado o Open Access.

- A tipologia dos artigos é variada: originais; revisões; meta-análises; editoriais; casos clínicos; perspectivas; imagens médicas; normas de orientação; ensaios clínicos, etc.

- Devem ser privilegiados artigos com boas amostras, multicêntricos, prospectivos.

- $\quad$ Tem que ser criada a cultura do respeito pelos prazos a par da procura de qualidade na revisão.

- A taxa de rejeição deve ter como referência um valor igual ou superior a $40 \%$.

- Deve existir ampla divulgação, formação e informação sobre os mecanismos processuais da obtenção da indexação e crescimento do Factor de Impacto (citações).

- Há uma necessidade urgente de melhorar os critérios segundo os quais a produção científica é avaliada por agências de financiamento, instituições académicas e outras. Os artigos devem ser avaliados pelos seus próprios méritos e não com base na revista onde são publicados.

- Há que disponibilizar uma série de métricas ao nível do artigo, para incentivar uma mudança em direcção à avaliação com base no conteúdo do artigo científico, em vez de métricas que se baseiam unicamente na revista em que foi publicado.

- Métricas alternativas: forte aposta nas medidas alternativas de impacto - novas métricas baseadas na Web Social para analisar a produção científica (Facebook, Linkedin, Twitter, Altmetrics).

- Adopção destas métricas, diversificando e enriquecendo o conceito de impacto e uso do artigo.

- Deve existir uma forte aposta nas novas tecnologias de informação e redes (Web 2.0, Facebook, Twitter, RSS, repositórios, comunicação social).

- As cinco revistas portuguesas indexadas na Medline têm disponibilizados quase 8000 artigos científicos: Revista Portuguesa de Cardiologia (3019), Acta Médica Portuguesa (2983), Revista Portuguesa de Cirurgia Cardiotorácica e Vascular (817), Revista Portuguesa de Pneumologia (647), Acta Reumatológica Portuguesa (497).

\section{CONCLUSÃO}

A publicação científica é uma actividade central e crucial no exercício da Medicina.

Deverá ser um complemento e uma extensão da prática da Medicina e da investigação básica, clínica ou de translação.

Nesta área, Portugal tem que procurar ser mais competitivo com o estrangeiro.

Todo o processo conducente à publicação científica em revistas com peer review é uma actividade muito específica.

O medical publishing deverá ser ensinado desde cedo nas Faculdades de Medicina. Todos os médicos, particularmente aqueles em formação, devem ter tempo alocado, a par da actividade clínica, para todo o processo do medical writing.

"Writing is thinking. To write well is to think clearly. That's why it's so hard". David McCullough (1933-).

"A great university has a dual function, to teach and to think". Sir William Osler (1849-1919).

"Avoid writing too much or too little". Sir William Osler.

"Revision is hard". Sir William Osler.

"There is no job description for the Editor". Richard Smith (Editor-Chefe do British Medical Journal de 1979-2004).

\section{AGRADECIMENTOS}

Agradecemos a colaboração de Jorge Crespo e Ivo Furtado. 
Rui Tato MARINHO, Helena DONATO, Fernando FERNANDEZ-LLIMOS, João MASSANO, José Manuel SILVA, Miguel ALMEIDA, José CARONA CARVALHO, Tiago VILLANUEVA, João Eurico FONSECA

\section{Think Tank: Relatório Estratégico sobre Publicação Científica Biomédica em Portugal Acta Med Port 2014:27:1-3}

Publicado pela Acta Médica Portuguesa, a Revista Científica da Ordem dos Médicos

Av. Almirante Gago Coutinho, 151

1749-084 Lisboa, Portugal.

Tel: +351218428 215

E-mail: submissao@actamedicaportuguesa.com

www.actamedicaportuguesa.com

ISSN:0870-399X | e-ISSN: 1646-0758

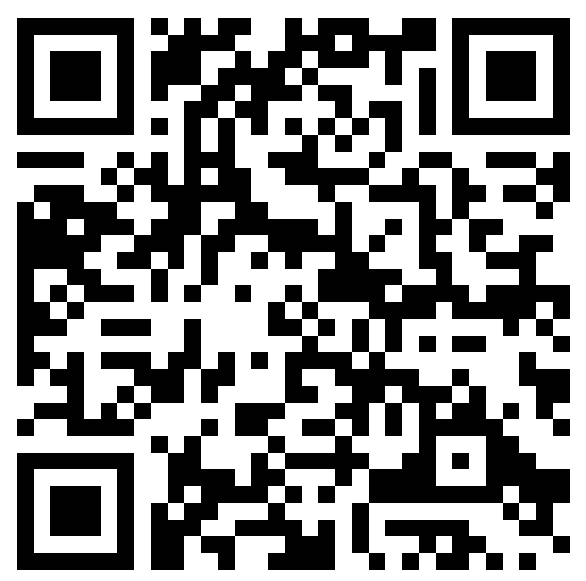

